Int. J. Electrochem. Sci., 12 (2017) 9007 - 9016

\title{
Corrosion and Electrochemical Impedance Properties of Ti Alloys as Orthopaedic Trauma Implant Materials
}

\author{
Xinqing Guo ${ }^{1}$,Huiming Shi ${ }^{2}$ and Lifeng $X i^{3 *}$ \\ ${ }^{1}$ Department of Orthopaedics, Luoyang Dongfang Hospital, The Third Affiliated Hospital of Henan \\ University of Science and Technology, Luoyang, Henan, 471003, P.R. China \\ ${ }^{2}$ Ward 1, Department of Traumatic Orthopedics, Hanzhong Central Hospital, Hanzhong, Shaanxi, \\ 723000, P.R.China \\ ${ }^{3}$ Department of Joint Surgery, Yellow River Sanmenxia Hospital, Sanmenxia, Henan, 472000, \\ P.R.China \\ *E-mail: lifengluoyang@foxmail.com
}

doi: $10.20964 / 2017.10 .05$

Received: 31 May 2017 / Accepted: 26 July 2017 / Published: 12 September 2017

In this study, $\mathrm{Ti}-24 \mathrm{Nb}-4 \mathrm{Zr}-8 \mathrm{Sn}$, a titanium alloy used in orthopaedic trauma implants, was studied for its electrochemical corrosion performance (in weight percent) in a phosphate buffered saline (PBS) solution at $37{ }^{\circ} \mathrm{C}$ using electrochemical impedance spectroscopy (EIS), open-circuit potential (OCP) and potentiodynamic polarization strategies. A Ti-6Al-4V sample was compared with commercially pure titanium. The experimental data indicated that the spontaneous passivation of the specimens occurred as soon as they were immersed in the electrolyte. The passive region of the $\mathrm{Ti}-24 \mathrm{Nb}-4 \mathrm{Zr}-$ $8 \mathrm{Sn}$ sample was wider than those of the Ti-6Al-4V and pure titanium samples. Additionally, the corrosion current density of the $\mathrm{Ti}-24 \mathrm{Nb}-4 \mathrm{Zr}-8 \mathrm{Sn}$ sample was as low as that of pure titanium.

Keywords: Ti based alloy; Orthopaedic trauma implant; Electrochemical impedance; Corrosion behaviour; Open circuit potential

\section{$\underline{\text { FULL TEXT }}$}

(C) 2017 The Authors. Published by ESG (www.electrochemsci.org). This article is an open access article distributed under the terms and conditions of the Creative Commons Attribution license (http://creativecommons.org/licenses/by/4.0/). 